\title{
RESEARCH OF THE SI ENGINE WITH MULTISPARK CAPACITOR DISCHARGE IGNITION SYSTEM
}

\author{
Audris Šimakauskas \\ Vilnius Gediminas technical University \\ E-mail: audris.simakauskas@vgtu.lt \\ Received 2014-06-10, accepted 2014-09-10
}

\begin{abstract}
Modern ignition systems for spark ignition (SI) engine management systems require an extended (adaptive) spark with regulated spark discharge duration for reliable ignition of fuel mixture and elimination of misfired-cycles. Lean air-fuel mixtures and alternative fuels also require an improved ignition system. In order to meet the increased requirements for ignition systems there is a multispark capacitor discharge ignition (CDI) system developed with prolonged spark duration. Block diagram of CDI system is presented; the principle of the operation of the system elements is explained. Mathematical model of the processes of the CDI system are developed. Calculations of the CDI system, test data with four-stroke SI engine GA14DS (Nissan Sunny) and conclusions are presented.
\end{abstract}

\section{Introduction}

Modern automotive electronic ignition systems for spark ignition (SI) engine can be inductive discharge ignition (IDI) or capacitor discharge ignition (CDI). Most ignition systems used in OEM (original equipment manufacturers) cars are inductive-type discharge ignition. IDI systems are simple; the spark duration is a few times longer than in CDI case. It is known that longer spark duration is more suitable for the SI engine at low rpm and light load ( Б a c c 1984, Jacobs 1999). On the contrary, short spark is acceptable at higher revolutions and heavy loads. Long spark duration provides disadvantage as it causes extended spark plug erosion and wastes energy (Rager 2006). Modern electronic ignition systems allow regulation of spark duration depending on SI engine performance conditions. The modern ignition system generates one spark at high rpm, but it can generate a few sequential sparks per one ignition pulse (multispark) at low rpm (Piock et al. 2010). The frequency of the multispark pulses must be greater (about $2 \mathrm{kHz}$ ) than in case of one spark. CDI systems have advantage over IDI systems due to short charging time, especially in multispark case.

Experimental multispark ignition system was developed and its capabilities tested with a SI engine. 


\section{Experimental multispark ignition system and theory of operation}

Schematic view of the experimental CDI shows Fig. 1. The ignition system operates cyclically. Each cycle consists of 3 phases: energy storage (charging circuit charges capacitor); the rise of the voltage; spark discharge.

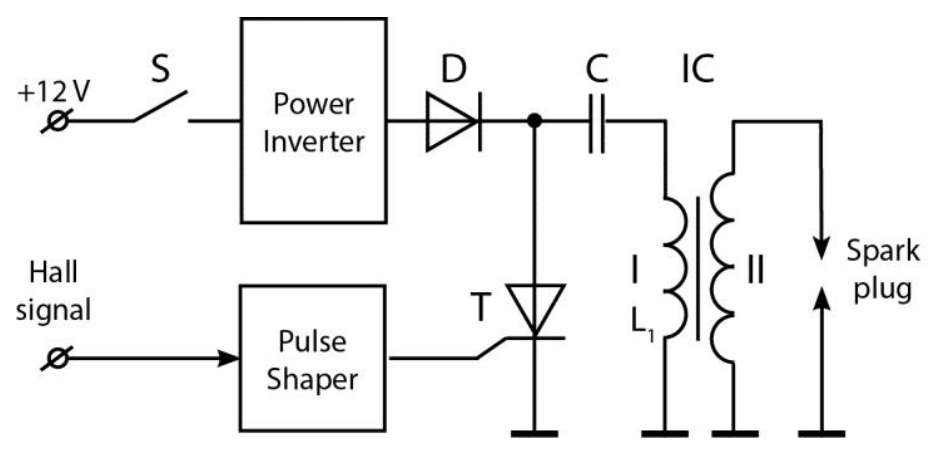

Fig. 1. The block diagram of the experimental CDI: S - ignition switch, D - rectifying diode, $\mathrm{C}$ - energy storage capacitor, IC - ignition coil with primary I and secondary II windings, $\mathrm{L}_{1}$ - primary inductance, $\mathrm{T}$ - thyristor

\section{The first phase of the operation of CDI}

First, when the switch $\mathrm{S}$ is turned on, the system voltage is raised up to 400500 volts by a power inverter. Then, the electric current charges the capacitor $\mathrm{C}$. The rectifier D installed inside the charging circuit prevents capacitor discharge before the moment of ignition occurs. Stored energy in capacitor is equal to: $Q_{C}=\frac{1}{2} C U_{C}^{2}$.

\section{The second phase of the operation of CDI}

The pulse shaper circuit receives triggering sensor signals and forms signal for the thyristor. At the ignition moment thyristor connects capacitor $\mathrm{C}$ to the primary windings of the ignition coil $\mathrm{L}_{1}$ and forms an oscillating $\mathrm{L}_{1} \mathrm{C}$ circuit. This $\mathrm{L}_{1} \mathrm{C}$ circuit produces alternating current. The action of triggering circuit stops the power inverter. After energy transformation in ignition coil, high secondary voltage can be obtained. The circuit model of the CDI at the second phase is shown in Fig. 2. 


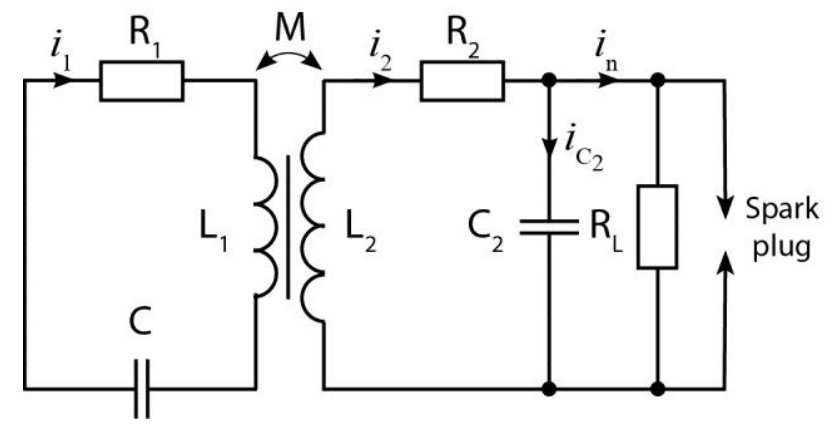

Fig. 2. The circuit model of the ignition system (second phase): $R_{1}$ and $R_{2}$ are the resistance of the primary and the secondary winding, respectively; $\mathrm{L}_{1}$ and $\mathrm{L}_{2}$ are the inductance of the primary and the secondary winding, respectively; $\mathrm{M}$ is the coefficient of mutual inductance between the primary and the secondary winding; $\mathrm{C}$ is the energy storage capacitor; $\mathrm{C}_{2}$ is the parasitic capacitances between the high-voltage wire and the shell; and $\mathrm{R}_{\mathrm{L}}$ is the leakage resistance

The differential equations of the processes of the second phase are:

$$
\left\{\begin{array}{c}
L_{1} \frac{d i_{1}}{d t}+R_{1} i_{1}+M \frac{d i_{2}}{d t}+u_{1}=0 \\
L_{2} \frac{d i_{2}}{d t}+R_{2} i_{2}+M \frac{d i_{1}}{d t}+u_{2}=0 \\
i_{1}-C \frac{d u_{1}}{d t}=0 \\
i_{2}-C_{2} \frac{d u_{2}}{d t}-\frac{u_{2}}{R_{L}}=0
\end{array},\right.
$$

The system of equations (1) is solved for $u_{2}$ :

$$
u_{2}(t)=A\left(e^{-\delta_{1} t} \cos \left(\omega_{1} t\right)-e^{-\delta_{2} t} \cos \left(\omega_{2} t\right)\right) .
$$

$\delta_{1}$ a $\delta_{2}$ - decay constants; $\omega_{1}$ ir $\omega_{2}$ - primary and secondary frequency. In this case: $\delta_{1}=0.12, \delta_{2}=0.46, \omega_{1}=11036, \omega_{2}=34525$. Constant $A$ can be represented:

$$
A=\frac{M U_{C} C}{L_{2} C_{2} \sqrt{\sqrt{\frac{L_{1}^{2} C^{2}}{L_{2}^{2} C_{2}^{2}}}-\frac{2 L_{1} C}{L_{2} C_{2}}+\frac{4 C M^{2}}{L_{2}^{2} C_{2}}+1}}
$$

The built-up secondary voltage calculated with Maple (arc phase) is shown in Fig. 3. $\mathrm{R}_{1}=1.6 \Omega, \mathrm{C}=0.82 \mu \mathrm{F}, \mathrm{L}_{1}=4 \mathrm{mH}, \mathrm{M}=0.45 \mathrm{H}, \mathrm{L}_{2}=30 \mathrm{H}, \mathrm{R}_{2}=10 \mathrm{k} \Omega$, $\mathrm{C}_{2}=50 \mathrm{pF}$.

Secondary voltage $u_{2}$ reaches breakdown voltage $u_{2 \mathrm{br}}\left(u_{2 \mathrm{br}}<0.67 u_{2 \mathrm{~m}}\right)$ and causes a spark to strike across the gap of the spark plug. Only a part of energy 
stored in capacitor $\mathrm{C}$ is used to charge secondary capacitances $\mathrm{C}_{2}$, i. e., $Q_{\mathrm{C} 2}=0.5 C_{2}$ $u_{2 \mathrm{br}}^{2}$.

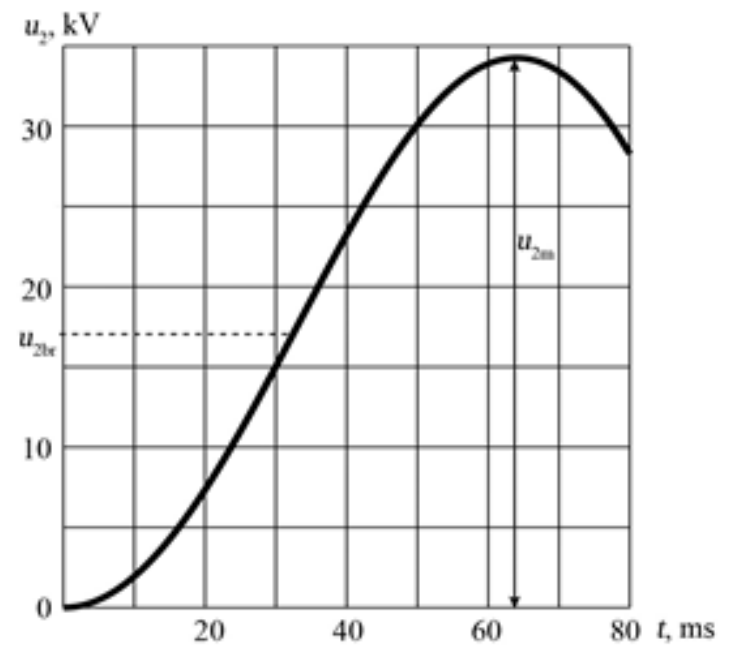

Fig. 3. The secondary voltage built-up at the second phase

\section{The third phase of the operation of CDI}

At breakdown phase the resistance of the sparkplug gap is reduced from hundreds of mega ohms to tens of ohms. Capacitances $\mathrm{C}_{2}$ discharge rapidly via sparkplug gap and spark current reaches hundreds of amperes for a short time. The short arc phase follows after breakdown. When spark current drops to about 100 milliamps, resistance of sparkplug gap rises to tens of kilo ohms and spark discharge transits to glow phase. Current in this phase supports only capacitance C. The circuit model of the CDI at the third phase is shown in Fig. 4.

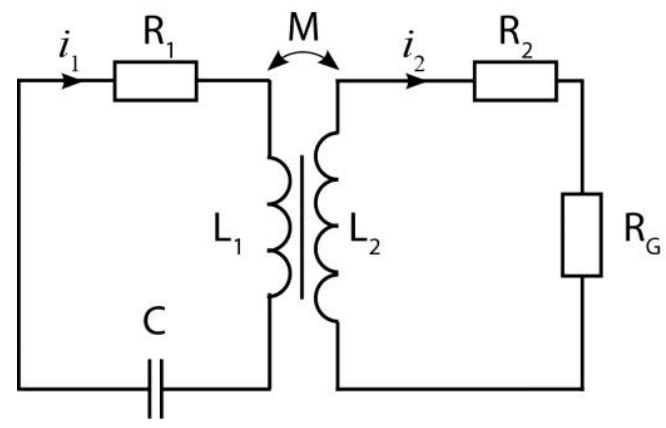

a

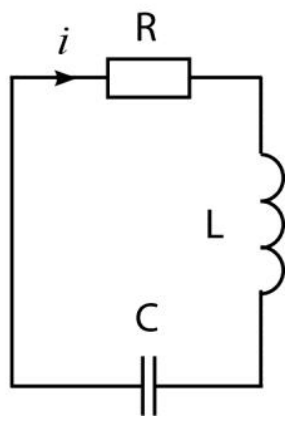

b

Fig. 4. The circuit model of the ignition system at glow phase: a) two circuits model; b) one circuit model. $\mathrm{R}_{\mathrm{G}}$ - resistance of sparkplug gap at glow discharge phase 
The two circuit models are transformed to one circuit model (Holden 2013). Transformed components (marked by apostrophe) are "transposed" into the primary winding. $L_{2 \mathrm{~S}}-$ leakage inductance of the secondary windings, $X_{\mathrm{L} 2}$ and $X_{\mathrm{L} 2 \mathrm{~S}}$ - impedances of the secondary windings). So:

$R=R_{1}+R_{2}^{\prime}+R_{G}^{\prime}$,

$L=L_{1}+L_{1 s}+L_{2}^{s}$,

$R_{2}^{\prime}+R_{G}^{\prime}=k^{\prime}\left(R_{2}+R_{G}\right)$,

$L_{2}^{f}=k^{f}\left(L_{2}+L_{2 s}\right)$,

$k^{\prime}=\frac{\omega^{2} M^{2}}{\left(R_{2}+R_{G}\right)^{2}+\left(x_{L 2}+X_{L n S}\right)^{2}}$.

Differential equation for the circuit model (Fig. 4, b) (Бессонов 2007):

$L \frac{d i}{d t}+R i-\frac{q}{C}=0$.

The roots of (8) are:

$p_{1,2}=-\frac{R}{2 L} \pm \sqrt{\frac{R^{2}}{4 L^{2}}-\frac{1}{L C}}$.

If we note $\frac{R}{2 L}=\delta$ and $\frac{1}{L C}=\omega_{0}^{2}$, the (9) looks:

$p_{1,2}=-\delta \pm \sqrt{\delta^{2}-\omega_{0}^{2}}$.

There are oscilations in ignition system after capacitor $\mathrm{C}$ discharge and the roots (10) are complex. So,

$\delta<\omega_{0}, R<2 \sqrt{\frac{L}{C}}$.

Note:

$\omega_{0}^{2}-\delta^{2}=\omega^{\prime 2}$

And the roots are:

$p_{1,2}=-\delta \pm j \omega^{\prime}$

The general solution of differential equation (9) is:

$$
i=\left(A_{1} \sin \left(\omega^{\prime} t\right)+A_{2} \cos \left(\omega^{\prime} t\right)\right) e^{-\delta t}
$$


At the initial conditions $t=0, i(0)=0, u(0)=U_{0}$. Thereby $A_{2}=0$ and

$$
A_{1}=\frac{U_{0}}{\omega^{\prime} L}
$$

The solution of differential equation (15) for current and voltage are:

$$
\begin{aligned}
& i=\frac{v_{0}}{\omega^{\prime} L} e^{-\delta t} \sin \left(\omega^{\prime} t\right), \\
& u_{L}=L \frac{d i}{d t}, \text { or } \\
& u_{L}=\frac{U_{0}}{\omega^{t}} e^{-\delta t}\left(\omega^{\prime} \cos \left(\omega^{\prime} t\right)-\delta \sin \left(\omega^{\prime} t\right)\right) .
\end{aligned}
$$

The calculated with Maple current and voltage at glow discharge and transformed to secondary circuit are shown in Fig. 5.
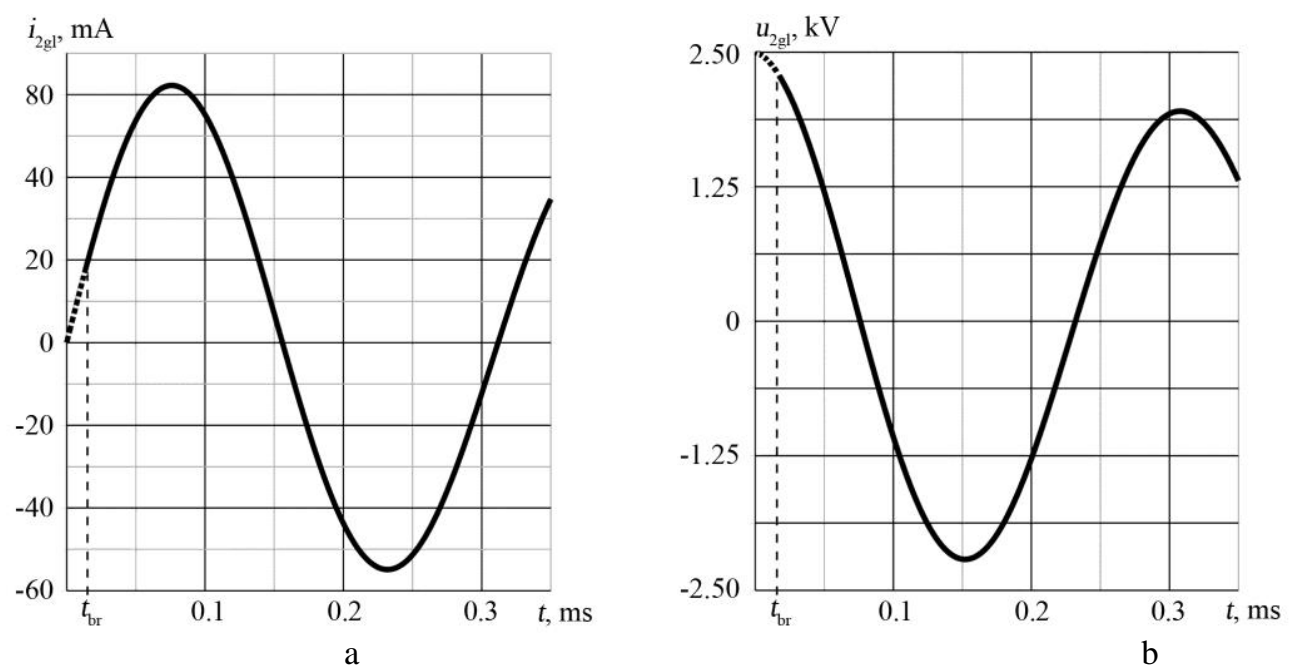

Fig. 5. The secondary current (a) and voltage on the ignition coil (b) at the glow discharge; $t_{\text {br }}$ - breakdown moment

\section{Experimental research}

The tasks of the experiments:

1) To identify and compare calculated and measured parameters such as $u_{2 \mathrm{~m}}, u_{2 \mathrm{br}}, i_{2 \mathrm{gl}}, u_{2 \mathrm{gl}}$ of the experimental ignition system;

2) Create the diagrams of the secondary voltage $U_{2 \max }=f(n)$, breakdown voltage $U_{2 \mathrm{br}}=f(n)$ and secondary voltage reserve $k_{r}=f(n)$ (the difference between the maximum secondary voltage $u_{2 \mathrm{~m}}$ and the breakdown voltage $u_{2 \mathrm{br}}$ );

3) To measure parameters of the multiple spark discharge (spark current, resistance, energy); 
Test bench with dynamometer brake and a four-stroke spark ignition engine GA14DS (Nissan Sunny) is used for experiments. Technical data of the engine: DOHC, 1.4 litre, compression ratio 9.5, it produces $55 \mathrm{~kW}$ at $6000 \mathrm{rpm}, 112 \mathrm{Nm}$ at 4000 rpm, spark plugs DENSO K20PR-U-11, sparkplug gap $0.75 \mathrm{~mm}$, carburettor Nikki 21L. Additional engine management device is electronic modulator for air/fuel ratio solenoid. Measuring devices: 2 channel automotive oscilloscope PicoScope 4223 (voltage measurement accuracy 1\%), cold wire air mass flow sensor SAAB 55557008, vacuum-meter, barometer, cooling and exhaust thermometer. Exhaust gas components like $\mathrm{CO}, \mathrm{CO}_{2}, \mathrm{NO}_{\mathrm{x}}$, hydrocarbons and airfuel equivalence ratio were measured by using AVL DiCom 4000.

As is seen in Fig. 3, calculated maximum of secondary voltage (peak secondary voltage) is $34 \mathrm{kV}$. Value measured with PicoScope is $35 \mathrm{kV}\left(\mathrm{R}_{\mathrm{L}}=\right.$ $\left.1.5 \mathrm{M} \Omega, \mathrm{C}_{2}=50 \mathrm{pF}, \mathrm{n}=1000 \mathrm{rpm}\right)$. The negligible difference is due to some presumptions at calculations.

The dependences of the secondary voltage $u_{2 \mathrm{~m}}$, breakdown voltage $u_{2 \mathrm{br}}$ and secondary voltage reserve $k_{\mathrm{r}}$ on rpm in the case of a single spark discharge of the experimental CDI are shown in Fig. 6. We can observe slight decrease of the secondary voltage with the increasing rpm. This is due to voltage losses in power inverter circuit.

The breakdown voltage $u_{2 \mathrm{br}}$ decreases as rpm increases because it depends on combustion temperature, cylinder air charge (which decreases), in-cylinder pressure (also decreases). Secondary voltage reserve $k_{r}$ increases as engine speed (rpm) increases (Fig. 6).

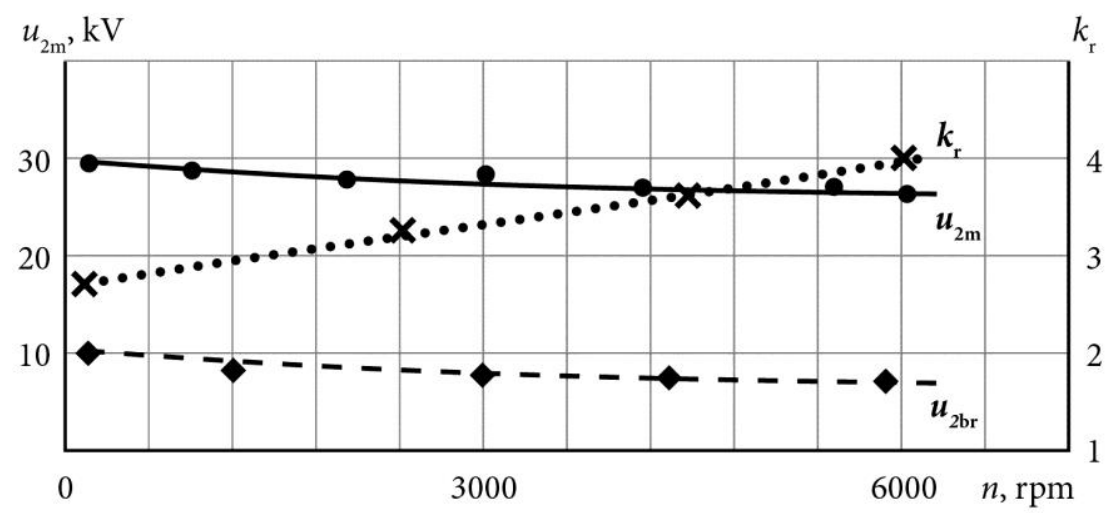

Fig. 6. The diagrams of the secondary voltage $u_{2 \max }$, breakdown voltage $u_{2 \mathrm{br}}$ and secondary voltage reserve $k_{\mathrm{r}}$

Oscillograms of the secondary voltage (a) and spark current (b) of the experimental ignition system in case of 4 sequential discharges (i. e. multi-spark) shows Fig. 7. Four discharges are generated by multiple discharge charged up to $450 \mathrm{~V}$ of $0.82 \mu \mathrm{F}$ capacitor via ignition coil. 

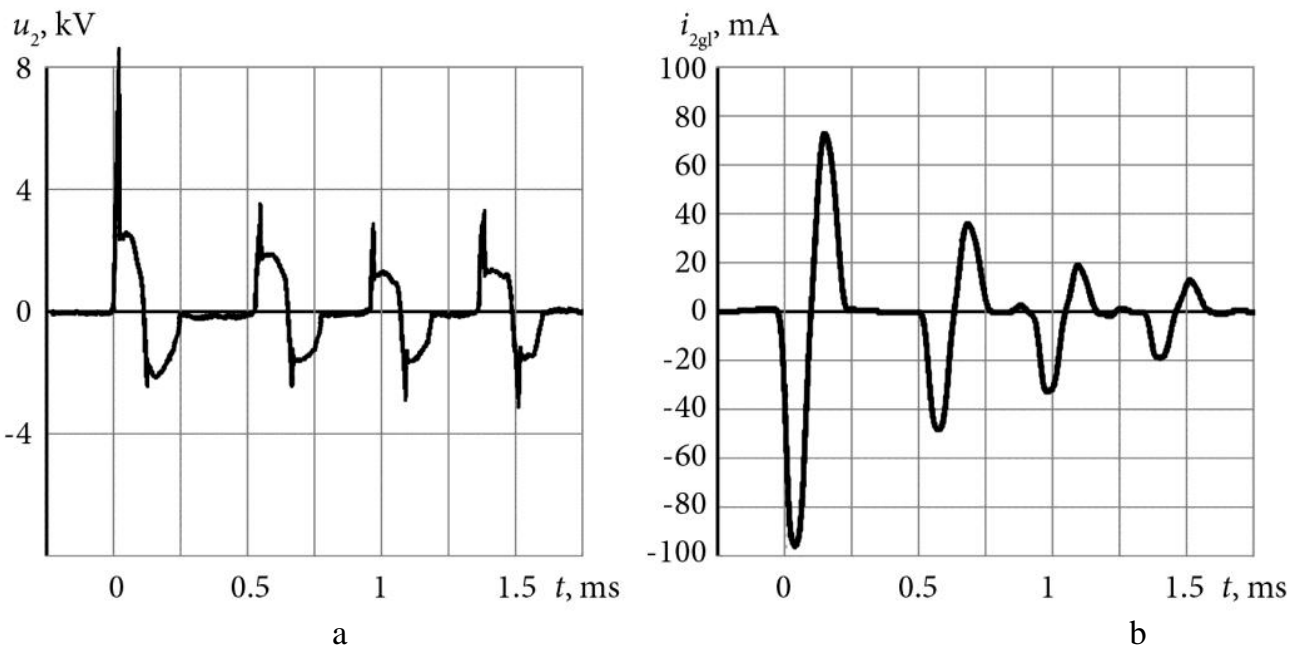

Fig. 7. The oscilograms of the secondary voltage (a) and spark current at glow discharge (b) of the experimental ignition system in case of 4 sequential discharges. Diagrams are taken with PicoScope 4223

As we can see in Fig. 7a, the breakdown voltage of the first spark discharge reaches more than $8.5 \mathrm{kV}$ while next 3 breakdowns reach only $3-4 \mathrm{kV}$. This suggests that in multispark case spark discharge does not recover completely until the second discharge occurs. The spark current of the first discharge in glow discharge reaches $100 \mathrm{~mA}$ and decreases to $20 \mathrm{~mA}$ at the fourth discharge spark (Fig. 7b). The total duration of the 4 spark discharge is $1.6 \mathrm{~ms}$ (including pauses between discharges), first spark energy is $22 \mathrm{~mJ}$, and total energy of the 4 sparks is equal to $37 \mathrm{~mJ}$.

CDI experiments with SI engine. The tasks are:

1) To determine the operating mode of the SI engine with CDI one spark discharge at which the increase fuel consumption and emissions.

2) To determine parameters of the CDI spark discharge under which the parameters of the SI engine are the same or better than with OEM ignition system.

3) Create the diagrams of the emissions of the SI engine.

It is widely known that ignition makes the influence on engine performance and emissions at low rpm and lean mixtures ( Б a c c 1984, Jacobs 1999, Holden 2013). For this reason, experiments with multispark CDI are mainly focused on this operating range of the engine.

Experiments are performed within the speed range from idling mode $(950 \mathrm{rpm})$ to speed increased to $1900 \mathrm{rpm}$. The fuel consumption $b$ dependences of air/fuel equivalence ratio $\lambda$ at the idle speed are shown in Fig. 8. Conclusions are:

1) When $\lambda<1$, there are no differences between ignition systems or number of spark discharge.

2) When $\lambda>1,2-3 \%$ fuel economy between one $(0.2 \mathrm{~ms})$ and four multispark (1.6 ms) discharges of the CDI system is observed. Advantage of the 4 sparks CDI system compared with OEM ignition system is a little more than $1 \%$. 

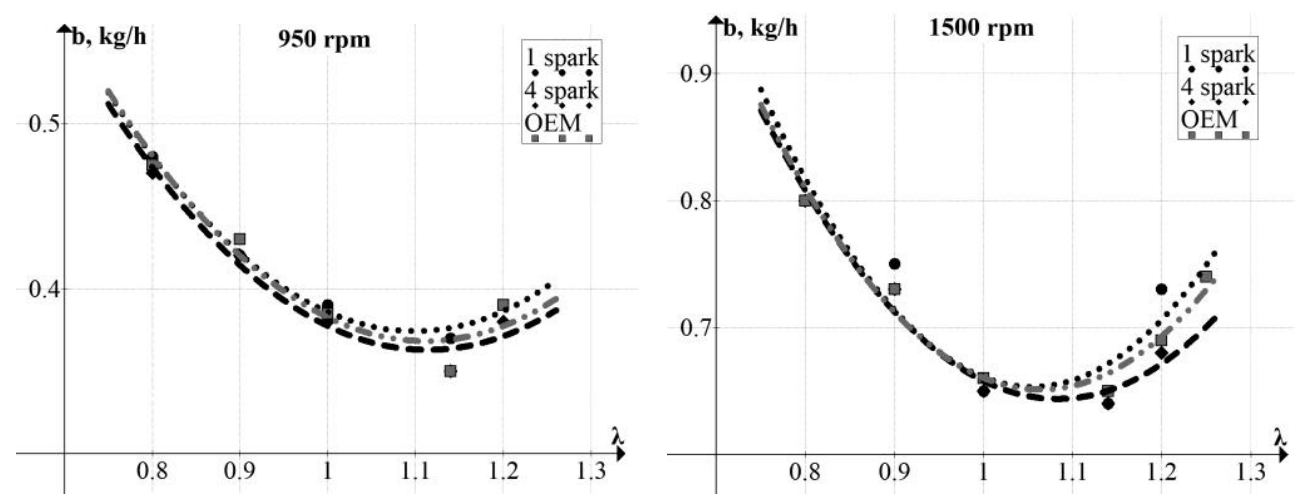

a

$\mathrm{b}$

Fig. 8. The fuel consumption $b$ dependences of air/fuel equivalence ratio $\lambda$ (optimal ignition timing)

Dependencies of hydrocarbons $(\mathrm{CH})$ concentration on the air/fuel equivalence ratio $\lambda$ are shown in Fig. 9. The hydrocarbons have a characteristic minimum at $\lambda=1-1.1$. $\mathrm{CH}$ highly depends on parameters of the spark:

1) At $950 \mathrm{rpm}$ (Fig. 9a), the minimum of the $\mathrm{CH}$ is $690 \mathrm{ppm}$ with one spark and it is reduced to 620 in the case of 4 sparks, i.e. $11.3 \%$ or $2.6 \%$ lower compared with OEM ignition (637 ppm).

2) As the idle speed increases to $1300 \mathrm{rpm}$ (Fig. 9b), $\mathrm{CH}$ concentration reduces while influence of the spark duration is even more visible. One spark system suggests the $\mathrm{CH}$ minimum of $612 \mathrm{ppm}$. When using 4 sparks, emission of $\mathrm{HC}$ reduces to $487 \mathrm{ppm}(25.6 \%)$. with using OEM ignition, it is $585 \mathrm{ppm}$ or $20 \%$ greater than in 4 sparks case.

3)
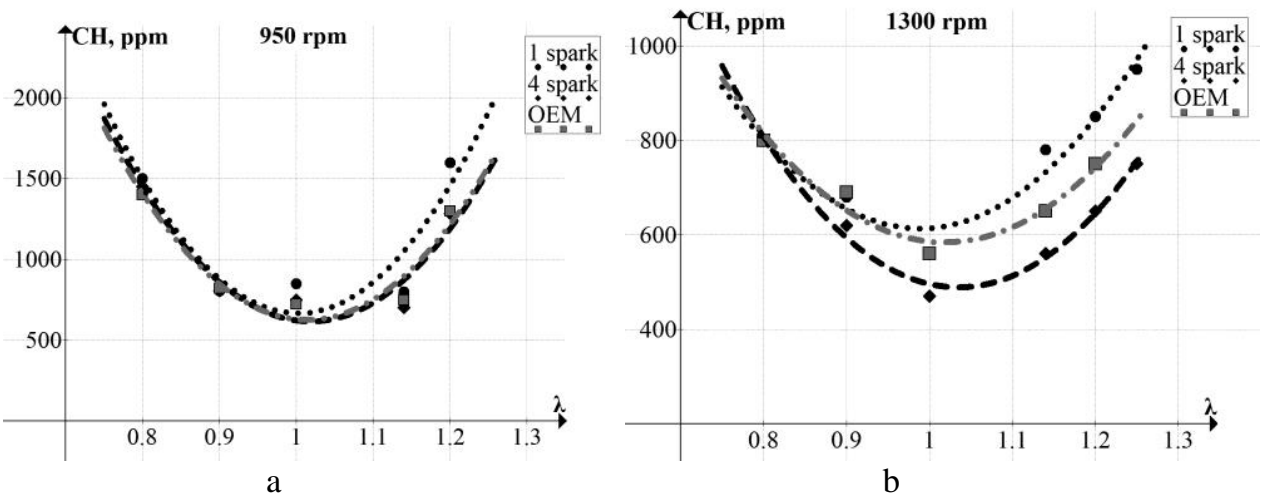

Fig. 9. Dependencies of hydrocarbons concentration on air/fuel equivalence ratio $\lambda$ at the idle

In Fig. 10 dependencies of hydrocarbons with increased engine load are given. The minimal concentration of hydrocarbons reduces due to increasing 
engine load. The increased both engine load from $6 \mathrm{Nm}$ to $15 \mathrm{Nm}$ and engine speed by $15 \%$ (from 1650 to $1800 \mathrm{rpm}$ ) the $\mathrm{CH}$ concentration reduce by $39 \%$.

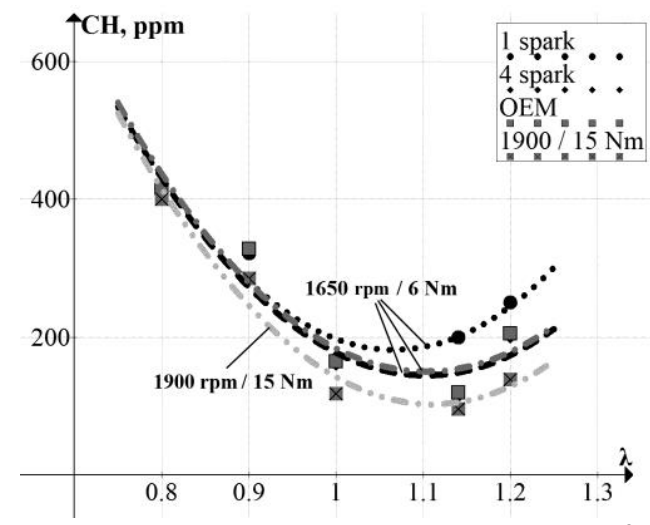

Fig. 10. The dependencies of hydrocarbons concentration on air/fuel equivalence ratio $\lambda$ at various engine performance conditions

$\mathrm{NO}_{\mathrm{x}}$ dependencies on air/fuel equivalence ratio $\lambda$ are shown in Fig. 11 (at idle) and Fig. 12 (with engine load). The concentration of the nitrogen oxides depends on $\lambda$, engine speed and load. No noticeable influence of the ignition system type or spark energy on $\mathrm{NO}_{\mathrm{x}}$ emissions was observed.

The $\mathrm{NO}_{\mathrm{x}}$ emissions have almost unchanged (about $60 \mathrm{ppm}$ ) at the idle and increased idle speed $(950-1900 \mathrm{rpm})$. With increasing $\lambda$, they arise faster when engine speed is lower and reaches maximum value of $170 \mathrm{ppm}$ (Fig. 11a). Maximum $\mathrm{NO}_{\mathrm{x}}$ level of $125 \mathrm{ppm}$ was measured when running at $1800 \mathrm{rpm}$ speed.
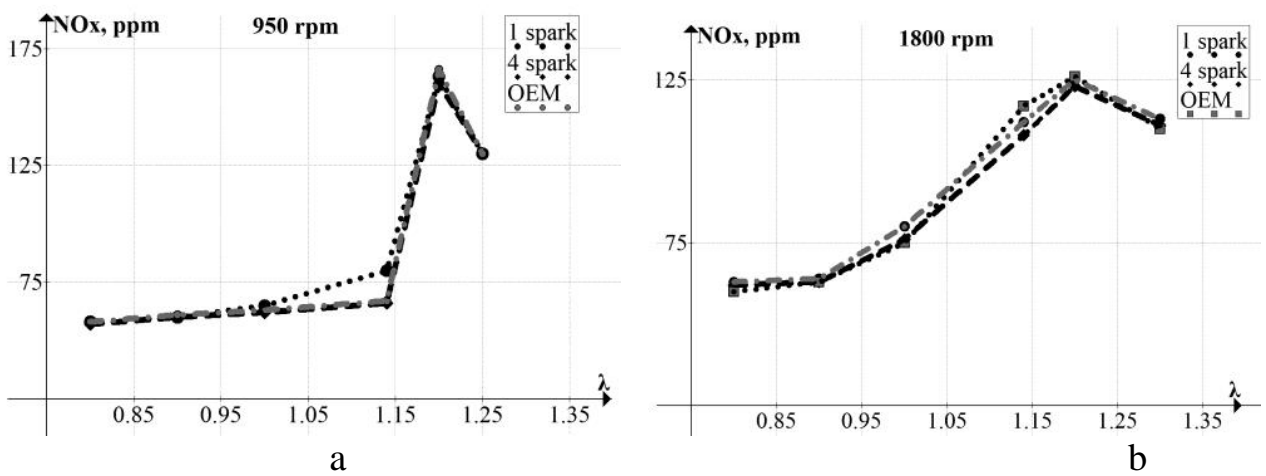

Fig. 11. Dependencies of the nitrogen oxides concentration on air/fuel equivalence ratio $\lambda$ at the idle

$\mathrm{NO}_{\mathrm{x}}$ emission was $100 \mathrm{ppm}$ at the engine load of $6 \mathrm{Nm}$ and 1650 rpm (Fig. 12) and it was higher than at idle (Fig 11). At $\lambda=1.05$, it has the maximum value of $300 \mathrm{ppm}$. When $\lambda$ increases, the concentration of nitrogen oxides reduces. With the engine speed increased to $1900 \mathrm{rpm}$ and load boosted up to $15 \mathrm{Nm}$, the $\mathrm{NO}_{\mathrm{x}}$ 
emissions increased: for rich mixtures $-500 \mathrm{ppm}$, maximum $-800 \mathrm{ppm}$ and for lean ones $-500 \mathrm{ppm}$.

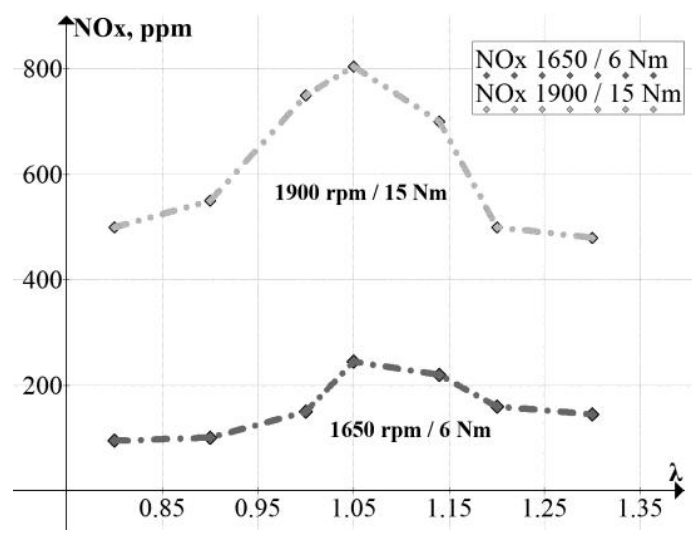

Fig. 12. Dependencies of the nitrogen oxides concentration on air/fuel equivalence ratio $\lambda$ at various engine loads and speeds

\section{Conclusions}

- It is known that fuel economy of the SI engine can be improved by the increased both duration and energy of the spark, especially when running at low rpm, light load and lean mixtures.

- Modern aftermarket CDI systems can generate high energy spark. This powerful spark without computer management leads to misfires and sparkplug erosion.

- Developed microprocessors allow creating adaptive spark for different operating modes of the SI engine. In this way, it is possible to obtain better fuel economy and reduce exhaust emissions.

- New electric circuit elements have been used in this innovative ignition system. This enabled to create variable spark - from one spark discharge (duration $200 \mu \mathrm{s}$, energy $22 \mathrm{~mJ}$ ) till sequence of the four discharges (duration $1.6 \mathrm{~ms}$, energy $37 \mathrm{~mJ}$ ). The experiments obtained on the engine running with original multispark CDI system are presented in this paper.

- The experimental results suggest:

- When $\lambda<1$ there are no differences between ignition systems (CDI or OEM IDI) or spark duration. One short spark is enough in the case of using CDI system.

$\circ$ When $\lambda>1$ four spark CDI system have advantage over one spark CDI or OEM IDI system: at no load.

- Fuel economy improves by 2-3\% within the speed range of 950-1900 rpm 
- At the idle (950 rpm), $\mathrm{CH}$ concentration reduces by $11.5 \%$ compared with OEM IDI system and by $25.6 \%$ compared with one spark case.

- The $\mathrm{CH}$ emissions are reduced by $27 \%$ due to replacement of one spark ignition system with four spark system used at loads up to $6 \mathrm{Nm}(1650 \mathrm{rpm})$ and $\lambda>1.2$. There is no difference observed when comparing four sparks CDI and OEM IDI systems.

- As experiments with SI engine have shown, four spark discharges are acceptable mainly at low both speeds and loads of the SI engine. And vice versa, one short spark discharge of the CDI system is sufficient when running at higher speeds and loads.

\section{References}

1. Holden, H. 2013. Capacitive discharge ignition vs magnetic discharge ignition. Available from internet: http://www.worldphaco.net/

2. Басс, Б. А. 1984. Повышение топливной экономичности бензиновых двигателей увеличе-нием энергии источника искрового зажсигания. Москва: Российская государственная библиотека. Available from internet: http://dlib.rsl.ru/01003435484

3. Jacobs, C. 1999. Performance ignition systems: electronic or breakerpoint ignition system tuning for maximum performance, power, and economy. New York: HPBooks, $160 \mathrm{p}$.

4. Piock, W. F., Weyand, P., Wolf, E., Heise, V. 2010. Ignition Systems for Spray-Guided Stratified Combustion. Available from internet: http://delphi.com/ pdf/techpapers/2010-01-0598.pdf

5. Rager J. 2006. Funkenerosion an Zündkerzenelektroden, PhD University Stuttgart

6. Бессонов, Л. А. (2007): Теоретические основы электротехники. Электрические цеепи: учебник. Москва: Гардарики, 701 с. 